\title{
El acuario de-Clara
}

\author{
Aquarius | Kleber Mendonça Filho | 2016
}

\author{
María Daniela Cormick*y Carla Pierri** \\ Universidad de Buenos Aires
}

Recibido: 15 de febrero 2017; aceptado: 28 de febrero 2017

\begin{abstract}
Resumen
Este ensayo busca compartir debates, contradicciones e interrogantes que nos generó el film Aquarius, a partir de nuestras trayectorias y experiencias como trabajadoras del sistema público de salud. Desde la construcción interdisciplinaria, reflexionamos sobre temáticas y conceptos como género, clase social, etnia, raza, identidad/ alteridad, lógicas y subjetividades de época, gentrificación. El resultado fue la apertura de preguntas e interpretaciones diversas de las historias que se entrecruzan en una compleja trama a partir de la figura de Clara, la protagonista. Utilizamos tres niveles de análisis, vinculados y jerarquizados: un nivel macro, vinculado a la lógica mercantil y al modo de producción, otro referido a las relaciones sociales (institucional) y, el último, de vida cotidiana (particularización de lo genérico social, encarnado en el relato de situaciones del film). El desafío fue problematizar lecturas obvias y desde allí cuestionar nuestros propios mandatos en torno a lo femenino y la mujer. Proponemos en este recorrido, un poco abigarrado y laberíntico, recuperar escenas, diálogos, personajes que vinculamos -directa o indirectamente- con problemáticas sociales, urbanas, subjetivas, representativas de fenómenos extendidos y vigentes en nuestros espacios de intervención y formación, desde una mirada orientada al análisis crítico de los procesos diferenciales de salud- enfermedad- atención. Desde una tensión entre lógica mercantil - lógica de lo singular consideramos algunos de los interrogantes que vertebraron nuestro pensamiento: ¿cómo es posible resistir a la lógica mercantil imperante? ¿cuál es el sentido de hacerlo en soledad? ¿qué ocurre con la dificultad para construir horizontes colectivos? ¿qué es lo que enfrenta Clara?
\end{abstract}

Palabras clave: Mercantilización | Singularidad | Clase Social | Género | Alteridad | Procesos de Salud/Enfermedad/Atención

Aquarius' declaration

\begin{abstract}
This essay seeks to share discussions, contradictions and questions that the film Aquarius produced on us, on the basis of our backgrounds and experiences as workers of the public health system. From an interdisciplinary construction, we reflect on themes and concepts such as gender, social class, ethnicity, race, identity/ otherness, epochal logics and forms of subjectivities, gentrification. The result was the raising of different questions and interpretations of the stories that intersect in a complex plot from the figure of Clara, the main character. We use three levels of analysis, linked with one another and organized in a hierarchy: a macro-level, linked with the commercial logic and the mode of production; another one, referred to social relationships (institutional); and, finally, that of everyday life (particularization of the generic-social, embodied in the account of situations from the film). The challenge was to problematize obvious readings and thence to question our own mandates around the feminine and women. We propose on this path, a little rambling and confused, to retrieve scenes, dialogues, characters, that we link -direct or indirectly- with social, urban, subjective issues which are representative of phenomena existing and extended in areas of our intervention and training, from a perspective oriented to a critical analysis of the differential health- disease- care process. From a tension between commercial logic- logic of the singular, we consider some of the questions that organize our thinking: How is it possible to resist the prevailing commercial logic? What is the sense of doing it in solitude? What happens with the difficulty to build collective horizons? What is it Clara faces?
\end{abstract}

Keywords: Commodification | Singularity | Social Class | Gender | Otherness | Health-disease-care process

\section{Sinopsis}

Aquarius, de Kleber Mendonça Filho. Brasil, 2016. Clara Amorim de Melo (Sonia Braga) es una figura importante de la crítica musical, jubilada, que vive cómodamente en su departamento de la costa de Recife. A través de tres capítulos la película recorre aspectos de la vida de la protagonista, tomando como disparador su lucha para preservar su departamento, donde conserva sus recuerdos e historias. Clara resiste rechazando las ofertas de compra de su casa por parte de una poderosa empresa inmobiliaria que parece estar dispuesta a todo para demoler el edificio

* danielacormick@gmail.com

**decarlapierri@gmail.com 
Aquarius y construir un mega proyecto urbano. Desde el inicio en los años ochenta, con la protagonista como una mujer joven que finaliza su recuperación de un cáncer, la película avanza hasta la actualidad para presentarla promediando sus sesenta años -fuerte, independiente, activadando indicios de sus trayectorias y relaciones personales, sus intereses, preocupaciones, su filosofía y estilo de vida.

\section{¿Por qué escribir sobre Aquarius?}

La reflexividad es definida por Guber (2004) como una condición inherente del conocimiento que implica considerar al investigador/a dentro del campo de análisis "y poner en cuestión su mundo académico, cultural y social, que es su condicionamiento, a la vez que su posibilidad de conceptualizar la objetividad social". Es desde esta noción que nos posicionamos para pensar cómo nuestra formación profesional, experiencias personales, inserción laboral y trayectorias en salud tiñen las percepciones y el foco de nuestro interés y nuestras preguntas en torno al film, querramos reconocerlo o no. Y es por esto también que elegimos intencionalmente -por considerarlo así necesario- desarrollar la redacción desde este nosotras que construimos en cada encuentro de trabajo y seguimos compartiendo.

Quienes escribimos este artículo somos ambas trabajadoras del subsector estatal del sistema público de salud abocadas a las actividades de prevención, promoción de la salud/ salud mental colectiva, posición desde donde pensamos este escrito.

Aquarius nos convoca desde distintas aristas pero especialmente por la inagotable cantidad de preguntas que nos produce, porque al avanzar en los intercambios cada vez más percibíamos tensiones, contradicciones. Esta no es una película para mirar cómodamente e identificarse con sus protagonistas y enemistarse con sus oponentes. Nos convocó a compartir las más impensadas escenas de nuestras vidas, las relaciones familiares, afectivas, con nuestros cuerpos, con nuestras alteridades.

Mirar Aquarius e indagarla desde allí, más allá de lo cinematográfico y del ocio, alimentó el proceso complejo de desnaturalización, y el recorrido teórico y reflexivo de cuestionamiento de lo cotidiano (Guber, 2004). Desde una mirada construida en conjunto fuimos combinando el abordaje desde la psicología con un enfoque antropológico, ambos atravesados centralmente por nuestra experiencia compartida desde el campo de la salud, uno de cuyos pilares es el derecho a la salud.
¿Cuáles son las temáticas que nos surgían al conversarla? La perspectiva de género, siempre articulada a la categoría central de clase social, interculturalidad, etnia o raza, la lógica mercantil y las grandes corporaciones, los procesos macro, subjetividades y padecimientos de época, la no naturalidad de los cursos de vida desde los diferenciales procesos de salud- enfermedad-atención. ${ }^{1}$ Desde allí se disparó un amplio universo de preguntas. Buceamos en una búsqueda asociada a "dar cuenta de la alteridad", las distancias culturales y sociales, "lo informal, lo intersticial”, aquello no explicitado que nos surgía del intercambio y las múltiples interpretaciones, buscando lógicas de los sujetos más allá del sentido común y los paradigmas teóricos, desde una posible "perspectiva del actor", entendida como "universo de referencia compartido -no siempre verbalizable- que subyace y articula el conjunto de prácticas, nociones y sentidos organizados por la interpretación y actividad de los sujetos sociales" (Guber, 2004).

\section{Pensábamos que... pero también ocurre que}

Entre las múltiples contradicciones e incomodidades que sentimos a partir de la película, algunas se encuentran más explícitamente planteadas y otras parecieran simplemente "estar allí". El lugar de Clara como mujer, como profesional, madre, su relación con hijos, sus ausencias, la relación con su sobrino, la asimétrica y "educada" relación con su empleada y los trabajadores de la empresa constructora, el lugar asignado a los objetos, sus marcas e historias en contraposición a lo efímero, virtual, descartable. Esto nos llevó a pensar cierta contraposición entre una lógica mercantil capitalista/ de lo inmediato y casi sin historia, lo que sirve (útil), lo técnico-procedimental a una lógica de lo singular vinculado a la escritura de la propia historia/ vida.

Otro núcleo que se desarrolla es del modo de acercarse o cerrarse al encuentro con el otro en tanto alteridad, poniendo en juego las jerarquías sociales y estereotipos en términos de género, clase y etnia o raza. Lo hedonista, individualista, narcisista, y la ausencia de horizontes colectivos y de instancias de lo estatal.

Intentamos aquí compartir algo de estos intercambios.

\section{¿Por qué Aquarius?}

Arriesguemos. Podríamos pensar que Aquarius refiere al nombre del edificio donde transcurre casi todo el film 
y que constituye el centro de la disputa y conflicto del relato. Es ese edificio, sus paredes, las historias que entraña lo que lo convierte en un lugar que Clara no está dispuesta ni a perder ni a cambiar.

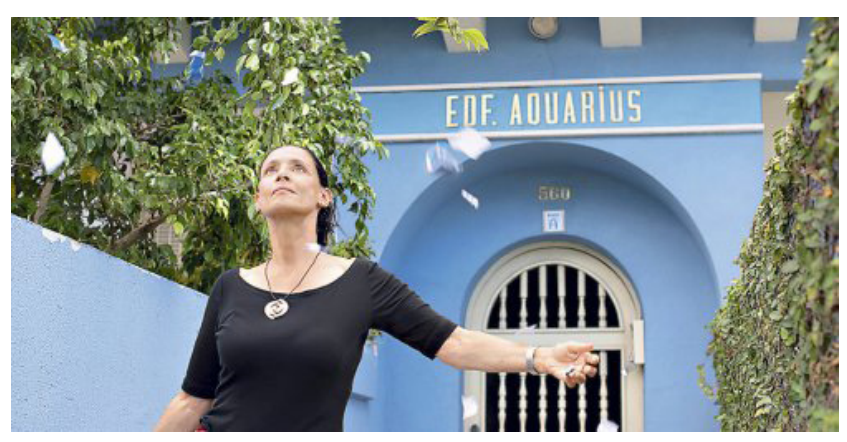

Asimismo se podría pensar la centralidad del ventanal del departamento de Clara -que da al frente del edificio y a la playa- como una de las paredes de una pecera, de un acuario. Por allí la protagonista mira el mar y las llegadas de los agentes de la constructora, pero también es el punto de vista desde el que el director elige narrar aquello que la protagonista no ve ni pareciera interesarle, pero ocurre a su alrededor. Desde esta lectura, la idea de acuario nos remite a una de las definiciones de la Real Academia Española que la entiende como un "recinto destinado a la exhibición de animales acuáticos vivos". Configuraría así un espacio que "exhibe" a la manera de una pecera transparente la vida cotidiana de una mujer particular que materializa lo genérico social de un momento y una sociedad dadas. Podemos leer este "acuario" desde un triple eje de análisis incorporando al entramado a un nivel macro y a un nivel institucional o de las relaciones sociales (Stolkiner, 1994). Creemos que en esta película resulta interesante, en un nivel de lo institucional (relaciones sociales en un momento histórico), abordar la perspectiva de género articulada a la categoría de clase social y a la de etnia, y a la vez en un nivel macro, en una época signada por una lógica de lo mercantil profundizada por corporaciones económicas -entre ellas las de los negocios inmobiliarios-, sin aparente intervención del Estado al respecto. Clara resiste a esa lógica imperante de consumo, mercantilista que posa de progreso. Su valoración de las marcas de la historia y de los objetos no por su precio sino por el afecto allí depositado, su modo de vivir el tiempo, el cuidado de sus momentos de ocio y placer en contraposición con las lógicas mencionadas, la ubican como "la loca del Aquarius". Ella responde: "la locura está ahí afuera”. ¿En la época tal vez?

Recordemos que el director elige situar su film en Recife, ciudad del nordeste de Brasil, conocida en la actua- lidad por la cantidad de emprendimientos inmobiliarios, en un país signado a fines de 2015 por una profunda crisis política alrededor de la figura de la presidenta Dilma Rousseff y su partido (Partido de los Trabajadores), con grandes movilizaciones que exigían su "impeachment" debido a acusaciones de corrupción, así como el de su vicepresidente (Temer). Dicho proceso también estuvo atravesado por pujas de los grandes grupos económicos con intereses particulares involucrados.

Volviendo a la trama singular, Clara es una mujer de su época (de su clase social, de su etnia, género) que en su singularidad, en sus contradicciones, búsqueda y deseo resiste a la avanzada inmobiliaria sobre su casa, que expresa una lógica capitalista creciente en su tiempo y su ciudad. La película nos encontró con una mujer viuda de sesenta y cinco años, profesional, periodista y escritora parcialmente retirada, que vive de rentas (tiene cinco departamentos y su jubilación), con un estilo de vida acomodado, con servicio doméstico casi a tiempo completo. Clara nada todas las mañanas en el mar frente a su casa, le preparan sus comidas, vive su tiempo de ocio con placer, tiene un grupo de amigas de clase alta -profesionales y con consumos de "alta cultura" semejantes a los suyoscon las que va a bailar, bebe vino escuchando "buena" música, maneja una camioneta, hace "ejercicios de risa" en un grupo, se vincula con sectores de la cultura, los medios, en muchos momentos se muestra rígida, tensa y el juego con su pelo y peinados parecieran hablar de sí misma.

Clara tiene capital económico, cultural, simbólico, social y ello le permite resistir todas las ofertas, amenazas y maniobras que le hacen para que venda su departamento.

En este sentido vale recordar una definición de sujeto de Toni Negri (1992) que justamente visibiliza que la materialidad sobre la que se construyen los sujetos es particularización de lo social. Negri plantea que el sujeto es un ser común y potente, común por sus determinaciones de época, potente porque no es estático y tiene la posibilidad como potencia de producir transformaciones.

\section{"Como un mensaje en una botella". Las marcas de lo humano}

Clara atesora discos de vinilo, fotografías de su familia, su casa, algunos muebles (como la cajonera) que portan según ella la textura de su vida, sus relatos, sus 
afectos, sus recuerdos. Ella repite insistentemente la importancia y el sentido que tienen para ella los recuerdos que acompañan los objetos.

En una entrevista donde le preguntan porqué conserva y prefiere los discos de vinilo por sobre formatos digitales, ella busca un disco que compró usado y relata su historia: cómo y cuándo lo adquirió, cuándo fue editado, qué marcas de uso tenía, y habla de un artículo periodístico que estaba en su interior. Remarca que con más de cuarenta años de antigüedad, aún se escucha perfecto, señalando un tiempo que no deteriora, no desvaloriza. Esa historia, esa singularidad, lo convierte en "un objeto especial”, y al artículo en "un mensaje en una botella". Ante la pregunta de la periodista por el anterior dueño del disco y el porqué del artículo Clara, casi riendo y quizás molesta, le responde que no lo sabe... y no importa. No importa porque lo que pareciera emocionarla es la posibilidad de imaginar historia, marca humana, metáfora, misterio. Así las huellas materiales de uso, los indicios de lo humano y de la vida es lo que ella pareciera preservar.

Ante la propuesta de un elemento virtual, nuevo, inmaculado, ella viene a la defensa de lo que tiene marca, historia, lo que no se descarta por viejo y tiene valor por la materialidad del rastro humano. Aparecen así varias contraposiciones: vinilo o pen drive, foto del ser amado en billetera o foto en el celular, llamada de voz o mensaje de texto. Ella no desprecia lo virtual, sólo que pide, añora y ansía la materialidad de los objetos y la presencia de las personas: "Ven a visitarme", "quiero escuchar tu voz", "estoy viva”. Nos surgen así preguntas: ¿qué de la historia está en el objeto? ¿se conserva la historia sin objetos? y en otro sentido ¿es posible recordar sin otros? ¿qué es lo que atesora Clara?

¿Son los objetos estrictamente necesarios para la construcción de su historia, de su identidad? ¿puede sostenerla sin ellos? ¿es necesario ver/ tocar para recordar²? ¿qué implica el afecto depositado sobre los objetos con historia en una época signada por la mercantilización, lo efímero y lo descartable? ¿Son los objetos o es la lógica de lo descartable lo que ella enfrenta?

En esta línea un diálogo nos resulta significativo. Al mirar fotografías en una reunión familiar, un miembro joven de la familia pregunta por ciertas fotos con los autos. El hermano de Clara explicita entonces una diferencia generacional en la relación con ese particular objeto. En un pasado añorado se posaba "como si el auto fuese un miembro de la familia", y desde un presente teñido de nostalgia los autos "ahora son sólo autos". Esta acla- ración indica una relación distinta con los objetos: uno es un tipo de objeto singular, parte de la historia, perdurable; el otro pareciera ser uno más del montón, cuyo valor reside en lo material, en su precio, más asociado al consumo que a un objeto único, libidinizado.

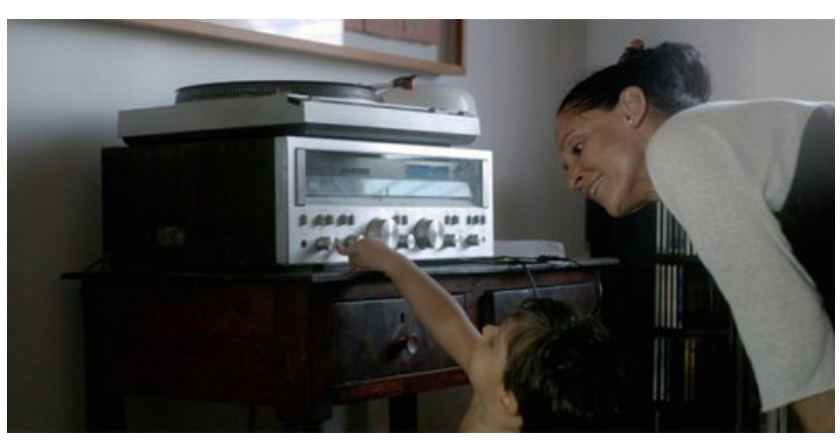

En esa misma línea, cuando el edificio Aquarius es calificado como antiguo, Clara retruca "vintage", y se opone la lectura de su hija referida al dinero ofrecido por la casa ("esa plata" por "este apartamento") desde un valor no monetario: "es el departamento donde ustedes crecieron".

Clara resguarda su casa, no quiere mudarse, no quiere otra en el mismo lugar, no tiene ningún interés en venderla, dice que sus recuerdos están allí. Resiste chantajes e intimidaciones de la constructora y rechaza toda negociación que le propongan. Clara llega a romper los sobres que le envían sin siquiera abrirlos, en un contexto en el que todos sus vecinos han vendido sus departamentos (en verdad, los han cambiado por los futuros departamentos que habrá allí) mientras ella ha permanece en el edificio. Ante este apego por su lugar y la resistencia frente a un poderoso grupo empresarial que intenta amedrentarla y atemorizarla repetidas veces nos surge como pregunta ¿por qué ella se ubica como adalid de la historia, como defensora de la calidez y cercanía de los vínculos y ha quedado sola en el Aquarius? Nos resistimos a caer en la tentación de interpretar una falsa y políticamente correcta dicotomía entre quienes irían al encuentro con lo humano, con la vida, lo "natural" y aquellos que preferirían la prolija, inmaculada, artificial y distante virtualidad. Sin embargo también creemos que la lucha por el departamento no es sólo por el departamento, sino que al igual que con los discos, con los autos, su posición pareciera contraponerse y resistir a una lógica mercantil de lo inmediato, descartable y a la moda. A la vez no podemos dejar de señalar que resiste en soledad, planteando el enfrentamiento en el orden de lo micro sin aparentemente poder pensar dicho problema en una trama mayor $y$, por ende, se ubica en un lugar 
casi quijotesco cuyo sentido resulta complejo y vale la siguiente pregunta: si bien ella enfrenta a una corporación y puede hacerlo por sus recursos múltiples, cuando demuestra al final de la película que está dispuesta a todo para ganar tal pulseada... ¿Quedaría viviendo sola en ese edificio gigante? Clara se enfrenta a las corporaciones, pero sólo en lo que estrictamente la incumbe, es un enfrentamiento parcial y situado sólo en relación a ella y sus recuerdos.

\section{Los encuentros de Clara. Alteridad}

Resulta difícil encontrar ejemplos donde Clara se contacte con otros de modo simétrico, abierto, entre iguales. Salta a la interpretación una valoración superior de su independencia y pretendida o esperada autosuficiencia. Pareciera haber en juego un narcisismo muy fuerte asociado no casualmente a cierta dificultad para vincularse con los otros. Todo lo hace sola: disfruta sola, resiste sola, ha quedado sola en Aquarius.

¿Podría quizás leerse esto en términos de alguien que registra aquello que la convoca y lo defiende y es valiente frente a situaciones que buscan arrebatárselo?

Clara busca oportunidades de encuentro, pero cuando estas se presentan pareciera manifestarse distante, escapar, levantar barreras. En una situación particular, Clara construye la posibilidad de salir a bailar con amigas, un ámbito donde se muestra dispuesta a conocer personas y generar vínculos. Baila con un hombre recientemente viudo, hablan, se gustan, se besan, pero el momento de intimidad concluye cuando ella frena la escena y relata su cirugía de mama. El hombre se detiene, se aleja y le ofrece llevarla a la casa. Ella elige volverse sola. Entendemos que su lectura es de que fue rechazada y bien así podría haber sido. Ahora bien ¿qué otras lecturas podrían pensarse? Más allá del hombre y su reacción ¿hay posibilidad de contar con el otro y continuar el diálogo, brindarse cierto margen de duda en relación a su propia interpretación? Al irse sola y rechazar la propuesta jes dignidad lo que se pone en juego? ¿es orgullo o miedo al encuentro con el otro? Esa sería una de las pocas escenas en que se podría haber comentado algo más sobre la enfermedad que tuvo o las marcas en su cuerpo. Su personaje lo cierra. Su lectura pareciera no abrir demasiadas preguntas. En este punto y considerando cierto narcisismo de Clara cabe traer un concepto que propone Derrida (2000) en relación a la hospitalidad y al encuentro con la alteridad. Este filósofo argelino-francés plantea que quien hospeda al acoger al otro en su desamparo se enfrenta a su propio desamparo, puesto que el otro en tanto alteridad nos cuestiona, nos interroga, nos interpela en nuestros saberes y certezas. ¿Cuán dispuesta está Clara a ser interpelada en sus certezas? ¿Podemos verla despojada de sus supuestos? Ante cierta apariencia de rigidez y reiteradas distancias vislumbradas en las relaciones con los otros pareciera que evita tales situaciones. Más bien, mantiene siempre una mirada altiva y actitud desafiante frente a los otros, poniendo un límite, con la "guardia en alto", hasta con cierta omnipotencia: nada parece asustarla ni superarla. Una frase de Paulinho da Viola que ella canta a su hija parece significativa: "hay personas con nervios de acero, sin sangre en las venas y sin corazón”.

A partir de la escena con el hombre viudo "rechazante" no encontramos muchos momentos en que ella vaya a encontrarse con un otro desde una situación de simetría, excepto con dos amigos, un periodista y una abogada, a quienes pide ayuda concreta para enfrentar a la constructora.

Clara, preocupada por el modo del encuentro, también muestra otra cara de esta temática: en su afán por atesorar recuerdos en su casa termina viviendo sola en un edificio "fantasma", sin poder construir con nadie una respuesta compartida contra el avance de la empresa ávida de lucro.

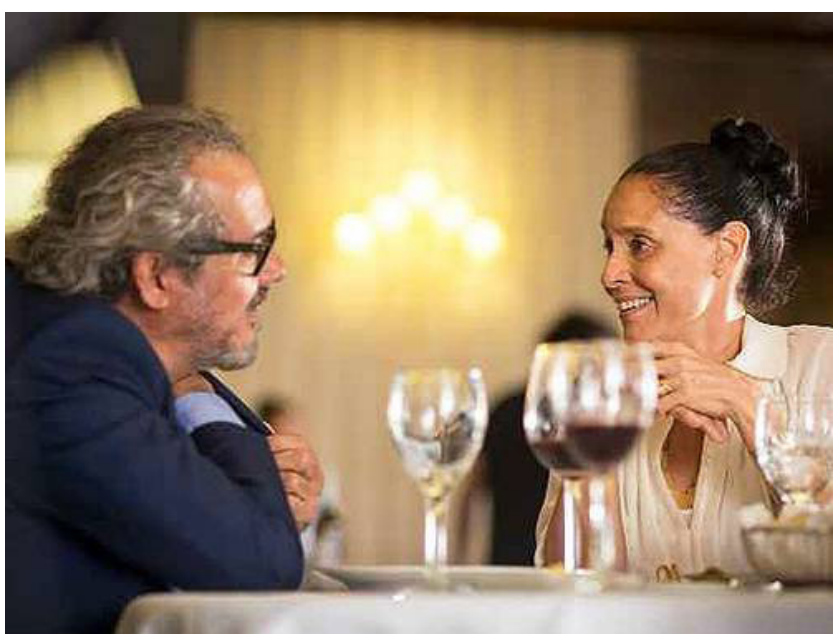

Ante ciertos reclamos y/o diferencias en relación a qué hacer con su departamento se acaba cualquier posibilidad de encuentro y pareciera construir un muro que la vuelve incuestionable, sin grietas.

Clara afirma, resuelve, señala: "los que están estresados son ustedes", dice a sus hijxs; Clara ofrece, pero parece hacerlo con la mediación de lo material y desde un ofrecimiento discursivo que la distancia de sus interlocutores. 
En dos escenas distintas, dos personajes le espetan a Clara, a modo de veladas amenazas: "no me conoces". ¿A quién conoce Clara? ¿quién la conoce a ella? ¿quién o qué constituye ese otro que la interpela?

La dedicatoria de Clara a sus hijos en un libro de su autoría es recuperada por uno de ellos como recurso para frenar una discusión entre ella y su hija, mostrándola como expresión de disculpa por el abandono que Clara hiciera a su familia por dos años. Nuevamente es un mensaje materializado, impreso, plasmado en el objeto, perdurable (que su hija acaricia luego de leer), pero no es buscado, pronunciado ni leído por ella y, como plantearemos más adelante, es confuso respecto al nivel de compromiso emocional, personal, maternal.

En la contraposición entre lo humano valorado desde la presencia, el contacto, lo material, y una virtualidad concebida como menos real, conversa con su sobrino acerca de una muchacha que él conoció por las redes virtuales y Clara plantea -quizás desde un posicionamiento que la ubica en el lugar de la experiencia, quizás con cierto halo de soberbia- que los encuentros de ese modo se parecen más a un "delivery" de personas.

Sus vínculos con hijos, amigas/conocidas, bañero, empleada doméstica parecieran de una prolija distancia, mientras en otros casos Clara se muestra incluso brusca, ácida, no tan cuidadosa.

Los momentos de mayor intimidad y calidez se representan con su sobrino. Con él se la ve relajada, afectuosa, en un vínculo que aparenta construirse desde el cariño, la ternura, y donde -como tía- pareciera ubicarse más felizmente.

La construcción y experiencia de la alteridad, ineludiblemente asociada a la identidad, remite a contactos concretos con otros sujetos en tanto integrantes de un grupo, una sociedad, dentro de configuraciones culturales e históricas particulares. Requiere -a pesar de diferencias más o menos inmediatas, visibles o explícitasreconocer a esos otros diferentes como iguales, llevando a "la pregunta por la igualdad en la diversidad y de la diversidad en la igualdad" (Krotz, 1994). Las situaciones de encuentro son oportunidades para la ampliación y profundización del conocimiento sobre uno mismo y su pertenencia, y es lo conocido lo que permite hacer accesible lo extraño en una anticipación que puede reforzar la distancia o atenuarla y alimentar reconfiguraciones de cercanía.

En esa dialéctica entre identidad y diferencia, con una mirada dinámica y relacional superadora de una diferenciación esencialista, se funda el asombro donde, desde lo propio, lo otro puede ser concebido, reconocido y conocido como tal (Krotz, 1987). Cualquier encuentro puede constituirse en un evento de asombro mutuo, donde indagar en las características, modos de vivir, transitar, construir el mundo de ese otro y su grupo, genere sorpresas y cuestionamientos movilizantes sobre el sí mismo y la propia sociedad (Krotz, 1987). Y desde allí es posible y necesario preguntarse por la identidad y la diferencia, lo ajeno/ extraño y lo propio/ familiar, los aspectos singulares y los fenómenos humanos, las condiciones de posibilidad del encuentro, la inteligibilidad y comunicabilidad, los criterios de acción y los límites, las causas y significados de esta alteridad, sus formas y transformaciones, su futuro y su sentido (Krotz, 1994).

Ahora bien ¿Hay asombro en el personaje de Clara?

\section{No tan distintos}

¿Cuán distintos son Clara y el arquitecto? Qué elementos los acerca y/o alejan? ¿Cuán distintas son Clara y su empleada? ¿Clara y su tía? ¿y su hija/os? ¿Cuánto de nosotras es Clara? ¿Qué interpela de Clara? ¿Cuánto querríamos ser Clara? ¿Por qué nos enoja y nos atrae? ¿Qué es lo que nos incomoda?

\section{"La loca del Aquarius", "la escritora", "la patrona". Identidad/es}

Las preguntas de los apartados anteriores nos llevan a pensar las implicancias del contraste entre una concepción de identidad como esencia, o como acto en tanto devenir en el encuentro con el otro. Identidad como un conjunto cerrado y estático de elementos, definitorios, definitivos, resultante de diferencias existentes u objetivas; o como un conjunto de estrategias que construyen, definen y mantienen límites, remarcando su carácter procesual, dinámico, mutable, histórico y relacional, social en sí mismo, pleno de contradicciones y transformaciones (Juliano, 1997). ¿Cuál/es es/ son la/s identidad/es de Clara? "Soy quien soy", dice Clara; "soy una viejita con una niña", "la viuda de tu padre soy yo", y a la vez es la que fue en su casa, es la que fue o es porque allí fue.

¿Clara desafía los estereotipos y la rigidez de ciertos "rótulos" que se espera que llene, como madre, mujer, adulta, abuela, profesional, jubilada, mulata? Desde esas distintas facetas de su figura, y en el contraste relacional con otros personajes (sus otros), pensamos posible vis- 
lumbrar los procesos identitarios de construcción, cambio, reconstrucción, y la diversidad de cada uno de esos roles o figuras, desarmando la idea de modelos unívocos. Partimos así de una visión múltiple y dinámica de pertenencias y referencias socioculturales (de clase, de género, étnica o racial, generacional, profesional/ laboral) de los sujetos en sus etapas, espacios, tránsitos vitales, dentro de una sociedad y época.

Las relaciones de clase y raza aparecen como las principales polarizaciones en términos de identidad/ alteridad, a nivel individual y social. No nos parece casual que ella es CLARA, y tomando una breve lista de sinónimos y definiciones, podríamos dar lugar a infinitas elucubraciones a partir de su nombre: Clara puede ser luminosa, brillante, viva, cristalina, diáfana, transparente, nítida, despejada, manifiesta, obvia, esclarecida, evidente, indudable, sincera y directa, sin reservas, franca, perspicaz, aguda, ilustre, honorable, libre de obstáculos, inteligible, fácil de comprender...

Clara se diferencia de Diego, el joven arquitecto de la constructora, en términos de género, de generación, pero también raciales. En una tensa discusión con Clara, él señala -por primera y única vez en el film-su condición de mulata como marca de inferioridad, ubicándola dentro de "una familia de piel más oscura, que tuvo que sudar" y luchar para "llegar a donde llegaron", y lograr el ascenso social. La protagonista da media vuelta y se retira, y es su empleada Ladjane, también mulata, quien se queda y responde antes de seguir a su patrona: "no puede tratarla así”. Por su parte Clara y Ladjane comparten características de género, generación, color de piel, pero entre ellas se juega la diferencia de clase. Lo racial en Clara, salvo en esta escena, parece diluirse por su posición social acomodada. Podríamos jugar aquí con una de las definiciones de la palabra que es su nombre: "que tiende al blanco, o se le acerca más que otro de su misma clase".

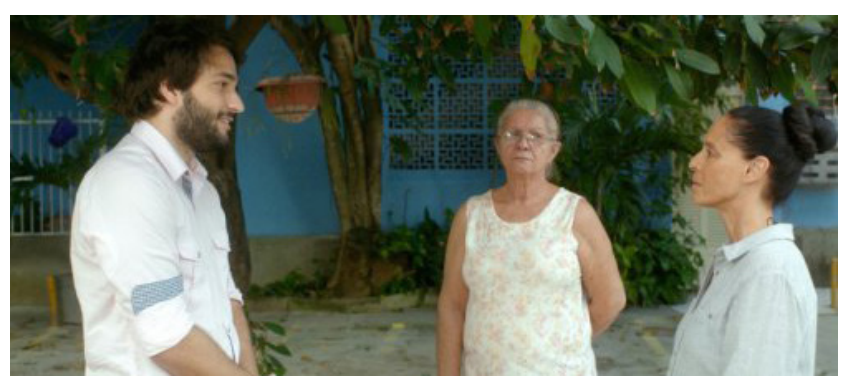

Pese a la existencia de políticas públicas tendientes a reducir las desigualdades raciales, persisten en Brasil diferencias marcadas entre los grupos identificados como mulatos o pardos y negros con la población blanca (Bomfin, 2014), que se delinean en la película. El concepto de raza pretende basarse en rasgos biológicos (que postula compartidos y homogéneos al interior de cada conjunto) para establecer divisiones y límites entre grupos humanos, y tiene profundos efectos sobre las relaciones sociales. La diferenciación, justificada a partir de rasgos fenotípicos superficiales (color de piel y ojos, pelo, contextura física), se funda en -y reproducedesigualdades y relaciones de dominación social, política, económica, religiosa. El racismo como construcción político ideológica, justifica estas relaciones de opresión y sometimiento con la naturalización de jerarquías y la esencialización de diferencias construidas y exacerbadas arbitrariamente.

Desde otras dimensiones, Clara se presenta para sus amigas y su hermano, con quienes comparte aspectos de clase y generacionales, como una mujer valiente y autónoma, decidida, libre y liberal, profesional reconocida. Frente a los personajes más jóvenes, puede combinarse lo anterior con otra imagen, quizás más conservadora, vinculada a cierta resistencia al cambio y la defensa de estructuras y tecnologías obsoletas, de un mundo analógico en desaparición o transformación.

Como madre (y abuela), las primeras apreciaciones nos la muestran parcialmente distante y se menciona una ausencia prolongada; nos detendremos en este rol clave para analizarlo con más detalle a continuación.

\section{“Es bueno tener un poquito de miedo" ¿Qué ven cuando la ven?}

Las figuras femeninas de la película, a diferencia de lo que sucede en muchas películas, son centrales y se muestran fuertes. Clara, su tía Lucia, su hija Ana Paula, sus amigas, su empleada Ladjane, Julia (amiga de su sobrino): representan modelos de mujeres independientes, no supeditadas a un hombre.

Cuando la tía de Clara, soltera y sin hijos, cumple setenta años, públicamente le reconocen sus valores y logros académicos y como persona. En simultáneo, se muestran imágenes estéticamente muy bellas de ella en su juventud teniendo relaciones sexuales, gozando en plenitud, en el contexto de la etapa de la revolución sexual. Pareciera que mientras quienes la agasajan relatan sus logros públicos, ella recuerda algunos de sus momentos de encuentro sexual y placer. Lucia sonríe ante los reconocimientos pero remarca que no fue mencionada parte de su vida en este racconto. En sus agregados al 
relato rompe con la imagen de mujer procerizada en su familia, y brinda con amor y picardía por quien fue su pareja durante treinta años: un hombre casado con otra mujer, ya fallecido. Tía Lucia transmite una actitud mucho más relajada, calma, "humana", quizás honesta con su deseo, fresca, frente a Clara quien suele mostrar cierta tensión o rigidez.

Ana María Fernández (1994) destaca que uno de los rasgos del siglo XX es la irrupción de las mujeres (de los sectores medios) en espacios tradicionalmente ocupados por hombres, y la revisión de los vínculos contractuales entre hombres y mujeres, siendo por ende un momento de producción de nueva subjetividad. Específicamente con respecto a las mujeres, Fernández plantea tres tránsitos: de heteronomía a autonomía económica (modelos de éxito y circulación del dinero), de heteronomía a autonomía erótica (redefinición activo-pasivo, de los objetos y sujetos del deseo) y de la maternidad como eje central de su proyecto de vida a una maternidad acotada. Se produce con ellos una crisis de los pactos que regían las relaciones familiares.

Anteriormente, el pacto sexual se sostenía en una subordinación económica y erótica de las mujeres burguesas que se alimentaba en tres mitos: el mito de mujer= madre, el de la pasividad sexual como inherente a la sexualidad, y el mito del amor romántico.

El personaje de la tía Lucia justamente pone en jaque estos mitos mostrando que más allá de sus logros académicos y personales ella había deseado profunda y sexualmente a un hombre. Es una mujer adulta, profesional, y aunque al no desarrollarse más su personaje no sabemos qué le ocurre con el mandato de la maternidad, se la ve tranquila, pícara con sus recuerdos, gozosa.

Por otro lado, de los hijos de Clara, es su hija mujer la que toma la palabra para transmitir la preocupación de los tres por la vida de su madre sola en el Aquarius. Es esta hija mujer la que la enfrenta y desafía también, la que se impone (por ejemplo, llevando al hijo a su cuidado, sin mayor consulta previa, sin pedir). Clara le señala la separación de su esposo en reiteradas oportunidades ¿por qué se le hace necesario remarcarle esa separación? ¿por qué frente a sus hermanos la muestra como la que necesitaría de su ayuda? ¿desde qué modelo la mira?

Pensando en diferentes modelos, experiencias, trayectorias, representaciones, posibilidades, roles desde maternidades y feminidades según clase y grupo social, también encontramos diferencias con su cuñada, de quien Clara se burla cuando le pide permiso al marido para ir a bailar.
¿Y qué ocurre con las mujeres de otra clase social? También son mostradas como mujeres fuertes, pero son mujeres que han quedado subordinadas a otras mujeres que "se liberaron" de los quehaceres domésticos en tanto profesionales y que les delegan las tareas. La empleada de Clara, Ladjane, es una presencia cotidiana que circula por la casa, le cocina, la asiste, cuida a su nieto y hasta la defiende. Si Clara puede ausentarse y no ocuparse de las tareas domésticas y de crianza es porque se apoya en estas otras mujeres que continúan dentro del mundo privado. Mujeres trabajadoras, muchas de ellas mulatas y negras, que se ocupan de las tareas de la reproducción de la vida. Empleadas que aparecen en las fotos familiares de Clara siempre a un costado, atrás, fuera de foco, cortadas. Ladjane, de clase trabajadora, pareciera cumplir mejor algunos cánones del modelo tradicional de mujer: además de su lugar en la vida doméstica, su rol materno y de cuidado. Ella muestra constantemente a su hijo, fallecido tiempo antes; en su cumpleaños la imagen del joven en un cuadro la acompaña.

Es aquí donde además podemos pensar la desigual distribución de los procesos de salud- enfermedad- atención (PSEA) según una triple inequidad: clase social, género y etnia (Breilh, 2009). Los modos de vivir, enfermar y morir de mujeres como Clara y Ladjane y sus familias retratan las desiguales trayectorias y condiciones de vida y producen subjetividades distintas, usos del cuerpo que generan patrones de desgaste diferenciales (Laurell, 1982). En este mismo sentido las enfermedades y padecimientos, y las respuestas a ellos, son hechos cotidianos que generan representaciones y prácticas estructuradas para entender, enfrentar, atender y resolver los daños a la salud. Los PSEA están configurados por múltiples dimensiones (biológicas, sociales, subjetivas) y llevan a la creación, desarrollo y resignificación de formas de atención según necesidades, posibilidades, condiciones de vida y salud de las comunidades, con prácticas y recursos diversos que son articulados funcionalmente a nivel de los sujetos y grupos (Menéndez, 1994).

Otra figura, es la de Clara. La conocemos paseando una noche en la playa, jugando a hacer zig zag en un auto, escuchando música. Luego de esa escena la vemos llegar a un edificio donde un hombre mira por la ventana de un departamento quizás esperándola. Entra a ese edificio y encontramos un evento familiar donde el hombre en cuestión la recibe y notamos que esa es su casa, el hombre es su marido, y el evento la fiesta de cumpleaños de su tía Lucia. La casa está llena de gente y de empleadas y ella se mueve con naturalidad ante una 
situación en la que los mandatos de género indicarían que debía haber estado como dueña de casa, anfitriona, a cargo de la organización. Clara no es la que atiende, Clara no pareciera ser la patrona que organiza y da órdenes. Es su marido el que la espera en la casa mientras ella pasea, es su marido el que cuida a sus hijos cuando ella se ausenta (por dos años), es su marido el que está atento a la dinámica del evento.

Clara es madre, sin embargo no es lo primero que se mencionaría de su historia porque de hecho el relato del film no lo toma como central, su maternidad no pareciera eje del proyecto de vida. Luego de la primera escena, donde tardamos en entender que ella era la madre de los chicos presentes, la veremos sólo una vez más con ellos, treinta años después en el mismo departamento.

Dicho encuentro pareciera cálido hasta que se menciona la preocupación por el departamento y se da lugar al reclamo de su hija por el "abandono" de dos años y un cuestionamiento acerca de su aporte económico al patrimonio familiar, subestimando su carrera y trabajo como escritora y periodista. Ante tal planteo, Clara ofendida la trata de "idiota" y posteriormente construye una respuesta en la que se desliga de tal apreciación y le devuelve que tal problema sería de la hija y no propio. Debido a esa ausencia, como mencionamos, les dedica a sus hijos un libro con la frase "Para Martín, Ana Paula y Rodrigo. Por las horas de placer/ ocio que les fueron robadas". A partir de esa dedicatoria surgen preguntas: ¿Quién robó las horas? ¿Por qué elige la palabra "horas"? ¿Por qué destaca que el tiempo robado es el de ocio? ¿Qué otros tiempos no nombra?

¿El mensaje es una dis-culpa? ¿Cree Clara que lo irrecuperable, lo perdido en su ausencia son los momentos de placer con sus hijos? ¿Cómo se juegan los distintos mandatos en relación a la maternidad y a su deseo al momento de escribir ese mensaje? ¿Su dedicatoria se nutre de responsabilidad, respuesta subjetiva o de culpa? ¿Por qué no responde a la pregunta de su hija por su ausencia y deja que sea uno de sus hijos el que a través del libro responda? ¿Qué relaciones existen entre su apariencia por momentos rígida y por momentos distante $\mathrm{y}$ el cumplimiento de mandatos como mujer, como madre, como profesional? La protagonista transgrede el mito de la madre abnegada (mujer=madre) y a la vez, al ser cuestionada su autonomía económica, reacciona profundamente defensiva (Fernández, 1994).

Los roles de género toman forma desde el conjunto de normas y prescripciones sociales y culturales sobre el comportamiento femenino o masculino, variando de acuerdo con el grupo cultural y étnico, la clase social, lo generacional. La representación más básica y tradicional remite a una división sexual del trabajo donde las mujeres, por parir hijos, son categorizadas como responsables de su cuidado asociando lo femenino a lo maternal, doméstico, emocional, contrapuesto a lo masculino como público, racional, activo. Esta dicotomía simplista masculinofemenino establece estereotipos que condicionan los papeles y limitan las potencialidades de las personas al estimular o reprimir los comportamientos en función de su adecuación al género. El concepto de género ayuda a desnaturalizar las características atribuidas a hombres y mujeres, visibilizando su construcción social y política en el marco de relaciones de desigualdad (Lamas, 1995).

Es así que podemos ver en Clara (y también en su tía) la representación de una nueva etapa de la vida, que no pareciera universal, sino que se vincula con una clase social: la madurescencia ${ }^{4}$. Son retratos de mujeres adultas distintas al modelo tradicional: independientes, activas, desenvueltas, "seguras de sí mismas", con deseo sexual, mujeres públicas, que han estudiado o pertenecen a algún ámbito de la cultura, mujeres cuyo eje de vida no pasa por la maternidad.

La frase que titula este apartado se la dice el bañero a Clara, y quizás sintetice una mirada social sobre lo que debería hacer o sentir una mujer en su situación.

\section{Lo extranjero: geografías de la desigualdad}

Un vínculo cotidiano de Clara es el que mantiene con Ladjane, quien trabaja para ella desde hace casi veinte años. Podríamos sentirnos tentadas a identificar allí un vínculo afectivo, de cuidado. Sin embargo en numerosas escenas se presenta una situación de desigualdad. Clara es una patrona "buena", con "buenos modales" pero a la vez sigue siendo su empleadora y ella su empleada. Nuestra protagonista va por la vida tranquila, relajada, atenta a sus placeres, y Ladjane la asiste, posibilitando ese confort ocioso. Clara recuerda la fecha del cumpleaños de Ladjane y ese día la saluda, en la misma escena donde al pasar le entrega en mano la taza que terminó de beber para sentarse al piano y "dedicarle" una canción de festejo.

Ladjane participa en cierto modo de la vida en casa de Clara, es una presencia casi constante, pero en relación de clara asimetría. Cuando en una reunión familiar de Clara se acerca a mostrar la foto de su hijo muerto en un accidente de tránsito, compartiendo de algún modo 
el motivo de charla, lo hace mientras les sirve vino a los presentes.

Clara concurre a la celebración de cumpleaños en casa de Ladjane, cruzando la línea del desagüe cloacal que separa la ciudad en un lado pobre y uno rico. En el festejo, Clara conversa con una amiga, patrona de la hermana de Ladjane por lo cual está allí, apartada del resto. Se muestra así la pertenencia a dos grupos que, marcados por la diferencia de clase, quedan delimitados por la cuñada de Clara: "nosotros las explotamos, ellas nos roban de vez en cuando”. La situación de opresión y explotación salta a la vista.

Los contrastes y desigualdades sociales de la ciudad y el país están visibles y dejan marcas en las relaciones donde se hacen carne a partir de asimetrías, diferencias, jerarquías y distancias. Se hacen presentes en la actitud del bañero, que explica a Clara que la custodian cuando nada "porque usted es importante", y también en los espacios de lo urbano: en la playa, entre barrios, en el uso y la presencia en el espacio público (la "irrupción" del grupo de jóvenes en el grupo de ejercicios de risa, o la aparición de un joven en su "bicicleta toda blanquita" señalado por el bañero como dealer para "nenes de papá”).

¿Cómo es posible el encuentro en un contexto como el de Recife en la película, con un esquema urbano atravesado por tales líneas de demarcación, con señales de pertenencia tan presentes en términos de clase?

El avance de los grandes proyectos e inversiones inmobiliarias destinadas a sectores de la población de mayores recursos económicos se enmarca en los procesos de transformación urbana, de modernización. La misma comienza con el reemplazo de los viejos edificios de las zonas mejor ubicadas (frente al mar, por ejemplo) por construcciones modernas como es el caso de los edificios vecinos de Aquarius. El que queda por demoler en su zona es el de Clara. Es imaginable que cuando ya no haya más Aquarius que reemplazar, se avanzará más claramente a los procesos de gentrificación (Blanco y Apaolaza, 2016). Aunque no se ponga directamente en debate en la película, son las desigualdades de clase las que determinan quiénes son los principales afectados por estos procesos -con claras implicancias políticas, socioculturales y subjetivas-, los desplazados en última instancia ${ }^{5}$, representados por Ladjane y su sector de pertenencia, quienes viven del lado pobre de la ciudad.

El Aquarius nunca fue un edificio de sectores "populares", pero su demolición se propone en relación a esa nueva ciudad que se expande en pos de una "recalificación de espacios urbanos estratégicos” (Blanco y Apaola- za, 2016). Es en este sentido que, indirectamente, el film nos volvió a remitir a nuestras experiencias de trabajo con personas y familias que atraviesan trayectorias habitacionales signadas por desalojos, en condiciones claramente desventajosas y alejadas de la experiencia de Clara.

Augé (2000) propone que los lugares antropológicos poseen al menos tres rasgos comunes: son identificatorios, relacionales e históricos. Podemos pensar en estos términos la relación -y construcción- que atraviesa el film desde la figura de Clara con el departamento, el edificio, la ciudad, con los elementos y las personas que la acompañan ¿es significativa su relación con la ciudad? ¿o se centra en su casa, como refugio, su playa...? Camino hacia la casa de Ladjane, su sobrino Tomás le pide que señale referencias de la ciudad para su amiga Julia, y Clara no parece tener mucho para decir más que marcar la distinción entre la zona pobre y rica. Las escenas la muestran en general en los mismos ambientes: su casa, la playa, la casa de su hermano.

¿Dónde se funda, en qué se basa, la identidad de esa ciudad? ¿son los edificios como Aquarius? ¿es esa línea divisoria? Si ese esquema urbano desigual resulta identificatorio ¿qué implicaría conservarlo? Ahora bien ¿de qué modo y quiénes se proponen transformarlo? El nuevo modelo urbano ¿constituye lugares en términos de espacios identitarios, relacionales, históricos o simplemente borra de un plumazo lo previo? Esta tensión entre las oposiciones progreso- memoria, renovaciónpreservación están atravesadas por una diversidad de luchas y desigualdades y no constituyen polos tan puros como se presentan en forma dicotómica.

\section{"Que la casa donde vives, [sea] el hogar de la alegría, un refugio en la tormenta"}

Cuando las personas de sectores acomodados de la película celebran los cumpleaños cantan una canción particular, conteniendo la frase que titula este apartado, que nos llamó la atención remitiéndonos a un modo de significar la casa, el hogar.

Clara no explicita un interés específico por el edificio o la ciudad, no plantea una defensa de la idiosincracia local o el resguardo arquitectónico urbano como hubiéramos esperado, sino que lo identitario, la historia, parecen anclados para ella en el departamento, desde lo estrictamente personal y familiar.

El edificio existe. 'Tanto existe que estás ahî', le dice Clara a Diego. Pero no existe como parte de una proyec- 
ción de futuro, no existe integrado al nuevo modelo urbano.... es un extranjero, un elemento extraño, ¿resulta una reliquia anacrónica para la lógica mercantil?

Aquarius se muestra en varias escenas contrastado como un edificio bajo, chato, ancho, con su entrada de jardín, frente a las modernas torres de vidrio y cemento que lo rodean y enmarcan la playa. Las imágenes de fotografías antiguas de la ciudad y la playa, en blanco y negro, son seguidas por recorridos aéreos que muestran una nueva configuración de torres sobre la playa, el trazado urbano con sectores diferenciados, carreteras, puentes.

El nombre "Nuevo Aquarius" le es propuesto a Clara para el futuro edificio, creyendo que un objeto material que se llame igual a otro sería para ella una solución de compromiso aceptable. Le plantean que así se podría "preservar la memoria del edificio que existió", señalando que el valor está en el terreno, la ubicación, y el nombre es un simbólico reconocimiento a lo local.

En su rol de propietaria, desde una lógica no ajena a la del sistema capitalista y liberal, de la propiedad privada y el derecho individual, Clara interpone otras prioridades en su decisión que exceden el interés monetario. A contramano de lo que se espera de una racionalidad económica y utilitarista, plantea un deseo -que por sus recursos puede sostener- distinto al esperable, que Diego ejemplifica al mencionar que mucha gente lo llama para saber si Doña Clara "tomó la decisión correcta". La decisión correcta es la que se vislumbra como la única posible considerando a Clara en su condición de mujer, de clase alta, "educada" y "preparada", madre, abuela, lo que vuelve obvio necesitar y valorar la seguridad y el confort. El arquitecto dice que no dejaría a su abuela o su mamá vivir en un lugar como Aquarius, sugiriéndole a Clara irse a un lugar "donde usted debería vivir", como es donde ellas viven, estandarizando necesidades y deseos, desde el "deber ser" de una lógica del consumo.

Clara, oponiéndose -parcialmente- a estas lógicas, o combinándolas desde su situación singular, debe justificar ante todos su elección. Aunque está en su derecho de propietaria el no vender, su decisión "obstaculiza el progreso", representado por el proyecto económico de modernización de la ciudad. ¿Podemos pensar esta tensión en términos de egoísmo/ derecho? En ambos casos, los límites de cada uno se marcan en relación a un otro: yo soy el otro del otro.

En otra dimensión, Clara también disputa la lógica mercantil al disfrutar su tiempo de ocio sin mostrarse culpable por ello. Un ocio singular, reflexivo, pausado, contemplativo, opuesto al entretenimiento estandari- zado, comercial, a la diversión consumista y vacía del "negocio del ocio" de un capitalismo que explota el trabajo de los individuos y también su tiempo libre (Freire, 2009). Clara disfruta del mar, la playa, los discos, la música, la escritura, el descanso, el paisaje, el baile, una bebida, charlas, lecturas, ejercicios en su casa. El ocio condiciona "la relación con uno mismo, con el mundo y con los otros" (Freire, 2009), y es político, subversivo, en tanto permite salir del utilitarismo del consumo, de un tiempo lineal, rutinario, apurado por el mandato de la eficiencia, resultando una crítica del "imaginario capitalista y su economía destructiva”, en tanto propone, como una elección vital, otros tiempos, no precipitados, no avasallantes. Pero, nuevamente, debemos decir que es la posición social de Clara lo que le permite ese disfrute, esas libertades, posibilitando modos de uso del tiempo impensables para quienes pertenecen a otras clases sociales.

El desenlace de la película se relaciona con el descubrimiento por parte de Clara de una última estrategia de la constructora: el uso de termitas dentro del Aquarius. ¿Por qué parece tan impactante encontrarlas, por qué el foco visual tan central en el film, el protagonismo? ¿qué se busca mostrar, qué representa esto para Clara y para la historia? ¿es sobre ella o la excede? ¿es sobre las transformaciones, sobre las desapariciones urbanas que pretende denunciar el director, asociadas a su propia historia?

En esa escena es donde se la ve a Clara más desarmada. ¿Es esa una metáfora de la desintegración, de los cruces de barreras a los que está dispuesto un sistema mercantilizador productor del derrumbamiento de aquellos que obstruyen sus planes? ¿Es una representación del cáncer, de lo que corroe/ carcome "desde adentro"? ¿Es la materialización de la inescrupulosidad de la lógica mercantil? ¿Es el sistema capitalista el cáncer de este mundo?

Y por último, como cierre: ¿qué decir de nuestro Aquarius, de nuestros recorridos en él? Los múltiples $\mathrm{y}$ diversos conceptos, enfoques, perspectivas, y especialmente preguntas, que pusimos en juego en estas lecturas amplias y singulares a la vez, tan abigarradas, entrelazadas, inagotables, son indicios de la complejidad del film, de sus vericuetos, de las cosas "no dichas", y del modo en que nos interpeló, y nos dejamos interpelar por él. Todas estas redes que se fueron abriendo podrían llevarnos quizás hasta un núcleo, una idea global que contenga y ordene.... O quizás no, y nos inviten a seguirlas, recorriendo e interrogando otros acuarios, como los senderos laberínticos e interconectados de las termitas. 
Referencias

Augé, Marc. (2000 [1992]). Los «No Lugares». Espacios del anonimato. Una antropología de la Sobremodernidad. Gedisa, Barcelona. Blanco, Jorge y Apaolaza, Ricardo. (2016). "Políticas y geografías del desplazamiento: Contextos y usos conceptuales para el debate sobre gentrificación”. En Revista INVI, 31 (88), 73-98. https://dx.doi.org/10.4067/S0718-83582016000300003

Bomfim, Leny Alves. (2014). Juventude negra no Nordeste do Brasil: Violência, Racismo Institucional e Proteção Social. Saúde da População Negra no Brasil.

Breihl, Jaime. (2009). “Introducción” y “Capítulo VII”. En Epidemiología crítica. Ciencia emancipadora e interculturalidad. Lugar editorial, Argentina.

Derrida, Jacques. (2000). La Hospitalidad. Buenos Aires, Ediciones de la Flor.

Fernández, Ana María. (1994). “Los pactos del amor”. En La Mujer de la ilusión. Paidós, Argentina.

Freire, Héctor. (2009). “Trabajo y ocio desde el cine. Entre el fetichismo de la mercancía y el proceso primario”. En Topía. Marzo 2009. https://www.topia.com.ar/articulos/trabajo-y-ocio-desde-el-cine

Guber, Rosana. (2004 [1991]). El salvaje metropolitano. Reconstrucción del conocimiento social en el trabajo de campo. Paidós, Buenos Aires.

Juliano, Dolores. (1997). “Universal/ particular. Un falso dilema”. En Globalización e identidad cultural. Ciccus, Buenos Aires.

Krotz, Esteban. (1987). “Utopía, asombro, alteridad: consideraciones metateóricas acerca de la investigación antropológica”. En ESTUDIOS SOCIOLÓGICOS V: 14.

_(1994). “Alteridad y pregunta antropológica”. En ALTERIDADES 4 (8), 5-11.

Lamas, Marta. (1995). "La perspectiva de género". En Revista de Educación y Cultura de la sección 47 del Sindicato Nacional de Trabajadores de la Educación,14-20. Guadalajara, México.

Laurell, Asa Cristina. (1982).”La Salud-Enfermedad como proceso social”. En Cuadernos Médico Sociales No 19. Rosario.

Left Hand Rotation, colectivo artístico. (2012). Gentrificación no es un nombre de señora. Universidad Complutense de Madrid. http://www.lefthandrotation.com/museodesplazados/

Menéndez, Eduardo. (1994). “La enfermedad y la curación. ¿Qué es la medicina tradicional?”, en Alteridades, 4 (7) 71-83. Universidad Autónoma de México, Iztapalapa.

Negri, Antonio. (1992). Fin de Siglo. Barcelona: Paidós.

Stolkiner, AIicia. (1994). “Tiempos Posmodernos, Ajuste y Salud Mental”. En Saidon O., Troianovski P.. (compiladores). Políticas en Salud Mental. Buenos Aires: Lugar Editorial. p. 25-55.

Yuni, José y Claudio Urbano. (2008). “Envejecimiento y Género: perspectivas teóricas y aproximaciones al envejecimiento femenino". En Revista Argentina de Sociología 6 (10) 151-169. http://www.scielo.org.ar/scielo.php?script=sci_arttext\&pi$\mathrm{d}=$ S1669-32482008000100011\&lng=es\&tlng=es

1 Los procesos de salud- enfermedad- atención- cuidado constituyen un universal que opera estructuralmente en todo conjunto social en formas diferenciadas, en el que "se construyen las causales específicas de los padecimientos, las formas de atención y los sistemas ideológicos (significados) respecto de los mismos”, y se desarrolla históricamente dentro de procesos sociales de producción y reproducción y relaciones de hegemonía y subalternidad. (Menéndez, 1994).

2 Así como con los objetos hay resguardo de la marca, nos preguntamos qué relación hay con aquellas en su cuerpo, con las cicatrices de su cáncer en la mama y de la que no se habla más que en una oportunidad en el relato. Asimismo, no podemos pasar por alto -aunque no nos detengamos aquí- el nombre del libro sobre Villa- Lobos del que Clara es autora: "Todas las músicas que no podemos ver".

3 "Pelas horas de lazer que lhes forman roubadas".

4 Este concepto reciente refiere a una etapa de transición de adultez o vejez temprana de las mujeres, activa y con la valoración de aspectos positivos del "envejecimiento". Se asocia a la búsqueda y confrontación con modelos y mandatos recibidos, con la interacción de múltiples factores como la experiencia de los cambios corporales asociados al paso del tiempo, la interpretación psicológica del ciclo vital, y el peso del “deber” ser de una mujer adulta. (Yuni y Urbano, 2008).

5 El desplazamiento puede darse también por aumento de precios en zonas modernizadas, por la no salida al mercado de las nuevas unidades, así como ser "auto-infringido" a partir de presiones simbólicas, forzadas por políticas urbanas, discursos y prácticas, como la invisibilidad y/o criminalización de prácticas sociales y culturales, o la limitación en el uso y la exclusión del espacio público. (Blanco y Apaolaza, 2016). 